\begin{tabular}{|l|l|l||}
\hline \multicolumn{2}{|c|}{ PublisherInfo } \\
\hline \hline PublisherName & $:$ & BioMed Central \\
\hline \hline PublisherLocation & $:$ & London \\
\hline \hline PublisherImprintName & $:$ & BioMed Central \\
\hline \hline
\end{tabular}

Getting Cre protein into cells

\begin{tabular}{|l|l|l||}
\hline \multicolumn{2}{|c|}{ ArticleInfo } \\
\hline \hline ArticleID & $:$ & 4316 \\
\hline \hline ArticleDOI & $:$ & $10.1186 /$ gb-2002-3-2-reports0009 \\
\hline \hline ArticleCitationID & $:$ & reports0009 \\
\hline \hline ArticleSequenceNumber & $:$ & 17 \\
\hline \hline ArticleCategory & $:$ & Paper report \\
\hline ArticleFirstPage & $:$ & 1 \\
\hline \hline ArticleLastPage & $:$ & 4 \\
\hline \hline & & RegistrationDate : 2001-12-4 \\
ArticleHistory & $:$ & Received \\
\hline \hline ArticleCopyright & $:$ & BioMed Central Ltd2002 \\
\hline \hline ArticleGrants & $:$ & \\
\hline \hline
\end{tabular}




\begin{tabular}{|l|l|l||}
\hline ArticleContext & $:$ & 130593322 \\
\hline
\end{tabular}

\section{Negar Jamshidi}

\section{Abstract}

A novel protein-based approach has been developed to import a cell-permeable form of the sitespecific recombinase Cre into undifferentiated and terminally differentiated mammalian cells

\section{Significance and context}

The bacteriophage-P1-derived Cre protein is a site-specific DNA recombinase that deletes pieces of DNA flanked by loxP sites. The use of the Cre-loxP recombination system to obtain conditional tissuespecific gene activation or gene knockouts is often hampered by restricted expression of the recombinase in the appropriate cell types and developmental stage. Likewise, tissue-specific Cre expression may impede further dissection of gene function in terminally differentiated cells. To overcome these limitations and allow easy non-invasive delivery of the Cre protein into intact cells, Jo et $a l$. have skillfully created a novel cell-permeable recombinant Cre by amalgamating protein transduction with Cre-loxP methodologies. The authors exploited the potential of certain amino-acid sequences to cross plasma membranes, thereby enabling the translocation of biologically active Cre protein directly into living cells.

\section{Key results}

The cell-permeable Cre protein was generated by fusion of the 12 amino-acid membrane translocation sequence (MTS) from the Kaposi fibroblast growth factor-4 (FGF-4) at the carboxyl terminus. The recombinant protein (His6-NLS-Cre-MTS) also contained a His affinity tag and a nuclear localization sequence (NLS) from simian virus 40 (SV40) T antigen. Immunocytochemical analysis revealed highly efficient import of the recombinant protein into the nucleus in mammalian cells. The authors also unequivocally demonstrated the ability of the recombinant protein to mediate recombination in cultured cells.

Jo et al. examined the cellular translocation of bioactive Cre recombinase in vivo after direct intraperitoneal or intravenous administration into transgenic mice (R26R) that will express $\alpha$ galactosidase ( $\alpha$-Gal) activity when induced by Cre-mediated recombination. They found $\alpha-\mathrm{Gal}$ expression in many tissues, including the brain, and no apparent toxic effects. On closer inspection, 
however, the efficiency of Cre-mediated recombination in vivowas found to be lower than that attainable from the expression of a Cre transgene.

\title{
Conclusions
}

Jo et al. conclude that the combination of Cre-loxP and a protein transduction approach not only allows rapid ablation or activation of gene expression both in vivo and ex vivo but also provides a comparatively easy way of obtaining temporal control. Furthermore, the rapid initiation of recombination upon exposure to the enzyme underscores the feasibility of efficient manipulation of gene function at later developmental stages. The new cell-permeable Cre could also serve as a reporter for quantitative assessment of protein traffic and uptake, in addition to its usefulness in the analysis of mammalian gene function.

\section{Reporter's comments}

The authors have shown a somewhat limited but significant capacity of recombinant Cre to enter mouse tissues in vivo. This approach should help supplement established non-invasive methods of delivering peptides and proteins to living cells, providing many ways to probe and/or block intracellular protein traffic and protein-protein interactions. Potential immune responses and toxicity associated with long-term introduction of foreign proteins in mice are, however, important issues that will need to be examined. Nonetheless, the speed and ease of translocation across the plasma membrane, low short-term immunogenicity and ease of detection of cell-permeable peptides could herald a paradigm shift towards protein therapy in combating human disease.

\section{Table of links}

\author{
Nature Biotechnology
}




\section{References}

1. Jo D, Nashabi A, Doxsee C, Lin Q, Unutmaz D, Chen J, Ruley HE: Epigenetic regulation of gene structure and functionwith a cell-permeable Cre recombinase. Nat Biotechnol. 2001, 19: 929-933. 1087-0156 